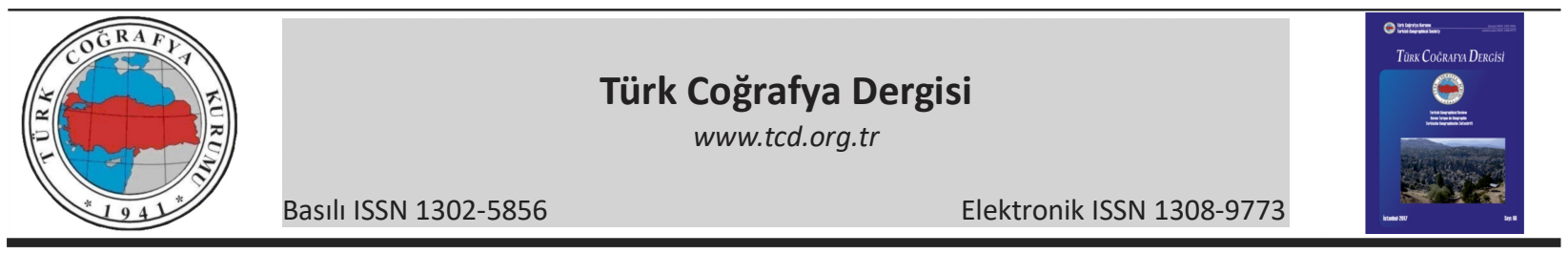

\title{
Uluslararası Coğrafya Olimpiyatı (iGeo) içeriği ve olimpiyatlara katılan ülkelerin coğrafya öğretim programlarının karşılaştırılması
}

\author{
Çağdaş Yüksel a Mesut Süzer*b \\ ${ }^{a}$ Istanbul Özel Amerikan Robert Lisesi, Istanbul. \\ 'istanbul Özel ENKA Okulları, İstanbul.
}

\section{MAKALE BILGi \\ Geliş/Received: 24.03.2017 Kabul/Accepted: 15.05.2017 \\ Anahtar Kelimeler: \\ Coğrafya eğitimi \\ Coğrafya öğretimi \\ Coğrafya olimpiyatları \\ Coğrafya müfredat}

*Sorumlu yazar/Corresponding author (M. Süzer)

mesutsuzer@enkaokullari.k12.tr

http://dx.doi.org/19.17211/tcd.300114

\section{ÖZ}

1996'dan yılından bu yana Uluslararası Coğrafya Birliği (IGU) Uluslararası Coğrafya Olimpiyatlarını (iGeo) organize etmektedir. Her ülke kendi ulusal olimpiyatını yaparak 16-19 yaş aralığında coğrafi becerileri üst düzeyde olan en iyi 4 öğrencisini seçerek bu organizasyona katılım gerçekleştirir. iGeo 3 aşamadan oluşmaktadır: yazılı test, multimedya testi ve arazi çalışması. Türkiye Ulusal Takım Seçmeleri IGU üyesi olan Türk Coğrafya Kurumu (TCK) tarafindan yapılmaktadır. Rusya'da düzenlenen iGeo2015 için TCK adına ulusal seçmeler tarafımızca hazırlanmış olup (i) bilim sınavı(TR), (ii) multimedya sınavı (EN), (iii) arazi çalışması sınavı (ENG) ve (iv) poster sunumu (ENG) olmak üzere Türkçe ve İngilizce 4 aşamalı olarak yapılmıştr. Türkiye genelinde Ortaöğretim Coğrafya ders içerikleri Milli Eğitim Bakanlığı Talim ve Terbiye Kurulu Başkanlığı'nca 2010 yılında yayımlanan "Coğrafya Dersi Öğretim Programı"na göre planlanmakta; bazı özel okullarda ise International Baccalaureate (IB) programları kapsamında "Bireyler ve Toplumlar" ana başlığı altında şekillendirilmektedir. Ortaöğretim sonrasında üniversite yaşantısını yurtdışında sürdürmeyi planlayan öğrenciler için bazı okullarda ise "Advanced Placement (AP) Human Geography" sınavlarına yönelik ders sonrası alışmaların planlandığı bilinmektedir. Bu öğretim programlarının genel amaçları (öğrencilerde coğrafi düşünce sistemi oluşturulması, coğrafi bakış açııının geliştirilmesi, gözlem, kartografik gösterim ve coğrafi analiz becerilerinin geliştirilmesi vb) birbirleri ile uyum içerisinde görünüyor olmasına karşın "ne öğretildiğinden çok nasıl öğretildiği" ve öğrencilerde kalıcı izli davranış değişikliği gerçekleştirip gerçekleştirmediği tartş̧ma konusudur. Uluslararası Coğrafya Olimpiyatı kapsamındaki günümüz küresel coğrafya yaklaşımlarının ülkemizdeki yansımaları da ayrı bir değerlendirme alanıdır.

\section{Giriş}

\subsection{Uluslararası Coğrafya Olimpiyatı (iGeo)}

Uluslararası Coğrafya Olimpiyat (iGeo), 1996 yılından bu yana Uluslararası Coğrafya Birliği (IGU) altında oluşturulan "Olimpiyat Komitesi" tarafindan organize edilmektedir. Her ülke 4 öğrenci ve 2 takım liderinden oluşan ulusal takımları ile olimpiyatlara katılmaktadır.

Olimpiyatın ana amaçlarını şu şekilde özetlemek mümkündür:

a. Gençlerin coğrafya ve çevre ile ilgili çalışmalara aktif ilgisini çekmek,

b. Coğrafi bilgi, beceri ve ilgi alanlarının niteliklerine dikkat çekerek ortaöğretim düzeyindeki okullarda Coğrafya'nın önemi ile ilgili değerlendirmelere olumlu katkıda bulunmak,

c. Farklı ülkelerden katılım gerçekleştiren gençler arasında sosyal etkileşimi ve uluslararası anlayışa katkıda bulunmak.

Olimpiyatın katılım koşulları ise şu şekilde özetlenebilir:

a. Olimpiyatın gerçekleşeceği yılın Haziran ayı sonunda 16 yaşından büyük - 19 yaşından küçük olmak,

b. Ortaöğretim öğrencisi olmak (ortaöğretimden mezun öğrenciler için olimpiyatın gerçekleşeceği tarihte üniversiteye kaydını yaptırmamış olmak),

\section{c. Ulusal Coğrafya Olimpiyatı sonucunda seçilmiş olmak}

d. İngilizce'ye hakim olmak.

Resmi dili İngilizce olan olimpiyat içeriği yarışmalar, sosyal etkinlikler ve gezileri kapsamaktadır.

Yarışma bölümü üç basamaktan oluşmaktadır: yazılı sınav, multimedya sınavı ve kapsamlı bir arazi çalışması sınavı. Açık uçlu sorulardan oluşan klasik sınav (Written Response Test) \%40, görsel destekli çoktan seçmeli sınav (Multimedia Test) \%20 ve arazi çalışması sınavı (Fieldwork Exercise) ise olimpiyatın yarışma bölümü değerlendirmesinde $\% 40$ ağırlığa sahiptir.

Ayrıca her yıl belirlenen bir tema üzerinden katılımcı ülkelerin hazırlıkdıkları kendi posterlerini sunduğu bir poster oturumu ve yine her ülkenin kendi kültürel değerlerini tanıtthğı bir otu- 
rum da gerçekleştirilmektedir.

Yukarıda belirtilen yarışma basamaklarında her katılımcı bireysel olarak yarışmakta ve bireysel puanlar elde etmektedir. Bunun sonucunda her katlımcı elde ettiği toplam puan üzerinden değerlendirilerek bir sıralama gerçekleştirilmektedir. Bu sıralamaya göre altın, gümüş ve bronz madalyalar sahiplerini bulmaktadır. 4 katllımcının toplam puanı ise ülke puanını oluşturmaktadır.

Yazılı sınav ve multimedya sınavında yer alan konu ve temaları 12 başlık altında toplamak mümkündür.

1. İklim ve iklim değişikliği

2. Afetler ve afet yönetimi

3. Kaynaklar ve kaynak yönetimi

4. Çevresel Coğrafya ve sürdürülebilir kalkınma

5. Yerşekilleri, peyzaj ve arazi kullanımı

6. Tarım Coğrafyası ve gıda problemleri

7. Demografi ve demografik değişimler

8. Ekonomik Coğrafya ve küreselleşme

9. Kalkınma Coğrafyası ve mekansal eşitsizlikler

10. Kent Coğrafyası, Kentsel Dönüşüm ve Kentsel Planlama

11. Turizm ve turizm yönetimi

12. Kültürel Coğrafya ve bölgesel kimlikler

Yazılı sınavda, yukarıda belirtilen başlıklardan 6 tanesi seçilerek (fiziki ve beşeri coğrafya dengesi gözetilerek) katılımcılara harita, sorgulama ve grafik becerilerini kullanmalarına yönelik yanıtları farklı uzunluklarda açık uçlu sorular yöneltilmektedir.

Multimedya sınavında ise 12 başlığın tamamı değerlendirmeye alınmaktadır. Arazi çalışmasında ise katılımcıların çalışma sahasında gözlem yaparak veri toplaması, sorgulama ile mekansal analizler yapması ve mekansal planlamalar yaparak ortaya koyacakları çözüm önerileri ile problem çözme becerileri göstermeleri beklenmektedir.

Hem yazılı sınavda hem de arazi çalışması sınavında katılımcıların harita ve grafikler ile ilgili okuma, çizim, analiz ve yorumlama becerileri, ek olarak tablo oluşturma ve veri işleme becerileri göstermeleri beklenmektedir.

\subsection{Türkiye Ulusal Coğrafya Olimpiyat (iGeoTR)}

Katılım koşulları içerisinde de belirtildiği üzere her ülke kendi ulusal coğrafya olimpiyatını organize etme sorumluluğu taşımaktadır. Türkiye'de ulusal coğrafya olimpiyatı organizasyonı Uluslararası Coğrafya Birliği üyesi olan Türk Coğrafya Kurumu (TCK) tarafindan gerçekleştirilmektedir.

2015 yılının Ağustos ayı içerisinde Rusya'da gerçekleştirilen 12. Uluslararası Coğrafya Olimpiyatı'na katılım için hazırlanan "Türkiye Ulusal Coğrafya Olimpiyat" aşağıdaki basamakları kapsayacak şekilde eliminasyon sistemi ile düzenlenmiştir.

1. Basamak Coğrafya Bilim Sınavı: 100 soruluk çoktan seçmeli sorulardan oluşan sınav içeriğinde öğrencilerin temel coğrafi bilgiler üzerindeki hakimiyetleri ve temel coğrafi beceri düzeylerinin ölçülmesi hedef alınmaktadır. Sınav dili Türkçe'dir.

2. Basamak Multimedya Sınavı: 40 soruluk görsellerle (harita, grafik, diyagram, fotoğraf, video vb.) desteklenen çoktan seçmeli sorulardan oluşan sınavda özellikle öğrencilerin coğrafi unsurları ve süreçleri güncel olaylarla ilişkilendirerek analiz edebilmeleri hedef alınmaktadır. Sınav dili İngilizce'dir.

3. Basamak Arazi Çalışması Sınavı: Bu aşamada, katılımcılar ile çalışma sahasında intiyaç duyabilecekleri veriler (saha ile ilgili fiziki ve beşeri coğrafya verilerinin yer aldığı bir kitapçık ile sahaya ait farklı içeriğe sahip haritalar) paylaşıldıktan sonra kat-lımcılar arazide kendi gözlemlerini yapmaktadırlar. Gözlem için ayrılan sürenin sonuna gelindiğinde katılımcıların kendi gözlemlerini, çalışma sahasında tespit ettikleri problemleri ve çözüm önerilerini paylaşacakları bir arazi çalışması sınavı uygulanmıştır. Sınav dili İngilizce'dir.

4. Basamak Poster Sunumu Sınavı: Bir önceki basamağı geçme başarısı gösteren katlımcılara farklı çalışma alanlarını kapsayan konu başlıkları verilerek bu basamakta jüri önünde sunum yapmak üzere akademik bir poster hazırlamaları istenmiştir. Hazırlanan posterin ve sunumun dili İngilizce'dir.

Poster sunumu sonrasında katılımcılar jürinin değerlendirmesi neticesinde elde ettikleri puanlara göre sıralanmaktadırlar. İlk 4 sıralamayı alan öğrenciler ulusal takımın asil üyelerini oluşturmaktadır.

\section{2. Ölçme ve Değerlendirme Sistemleri}

Değerlendirme, öğretim ve öğrenme döngüsü içinde ve öğretim süreci boyunca devam eden önemli bir ögedir. Ölçme ve değerlendirme yöntemleri sayesinde eğitim ve öğretim ortamlarının etkili olarak planlanması, uygulanması ve elde edilen sonuçlarında etkili ve hatasız olarak değerlendirilmesi sağlanabilir. Bu süreçte ölçme ve değerlendirme bir amaç değil, bir araçtır.

Bireyin sahip olduğu tüm bilişsel, duyuşsal ve devinişsel beceriler onun kapasitesidir. Bireyin bu kapasitelerinin olup olmadığı, sahipse ne ölçüde sahip olduğunun ortaya konulması için ölçme ve değerlendirme gereklidir.

Hem öğrenme hem ölçme ve hem de değerlendirme açısından eğitim hedeflerini oluşturan nitelikleri gruplara ayırmak mümkündür. Benjamin Bloom ve arkadaşları tarafindan yapılan zihinsel faaliyetlere dayalı sınıflandırma (Bloom Taksonomisi) bugün eğitimcilerin en fazla kullandıkları kaynaklardan biridir. Bu sınıflandırma bilişsel alan davranışlarını aşamalı olarak hiyerarşik bir yapı içinde basitten karmaşığa, kolaydan zora doğrudur. Bilişsel alandaki bu davranışlar şu basamaklara ayrılmaktadır;
a. Bilgi (Hattrlama, Belleme) Basamağı
b. Kavrama Basamağı
c. Uygulama Basamağı
d. Analiz Basamağı
e. Sentez Basamağı
f. Değerlendirme Basamağı

Bu sınıflandırmada alt düzey düşünme becerileri bilgi, kavrama ve uygulama basamakları ile üst düzey düşünme becerileri ise; analiz, sentez ve değerlendirme basamakları ile ifade etmekedir. Bireylerin düşünme sistemlerini harekete geçirecek etkili sorular hazırlanması ve sınav yapılarının bu sistematiğe bağlı kalınarak oluşturulması ölçme-değerlendirme süreçlerinin geçerliliği ve güvenirliliğini arttırmaktadır.

Uluslararası Coğrafya Olimpiyatı'nın uluslararası geçerliliğe 
sahip diğer ölçme ve değerlendirme sistemlerini kullandığı görülmektedir. Bu denli geniş çaplı ve kapsamlı ölçme-değerlendirme sistemlerinin yapısal özellikleri elbette öğretim programlarının da yapısını bizlere göstermektedir. Bundan dolayıdır ki ölçme-değerlendirme sistemlerinin hedefleri ve bileşenlerinin analiz edilmesi büyük önem taşımaktadır. Yapılan ölçme-değerlendirme çalışmalarına yönelik yapılacak analizler hedefin doğruluğunu belirleyecek ve tabiki bu hedefe ulaşma sürecini de etkileyecektir. Analizlerde ölçme-değerlendirme çaIışmalarının hangi bilişsel alan davranışları üzerinde yoğunlaşthğı ve içeriklerde yer alan bileşenlerin oransal dağılımını bilmek ve Bloom sınıflandırmasına dayanılarak ne derece gerçekleştirildiğini araştırmak bu çalışmanın ana hedefidir.

\section{Bulgular}

Pek çok ülke "ulusal coğrafya standartları"nı belirleyerek farklı sınıf düzeylerindeki öğrencilerin coğrafya ile ilgili hangi bilgi ve beceriye sahip olmaları ve bunları kullanarak ne yapabilmeleri gerektiği gibi konuları netleştirmiştir. Uluslararası ölçme-değerlendirme sistemlerinde yer alan hedef ve becerilerin bilişsel düzeydeki dağılımları ile bu ülkelerin coğrafya öğretim programları ve metotlarındaki dağılımın paralellik gösterdiği belirlenmiştir. Bu amaçla 4 farklı ölçme-değerlendirme sistemi analiz edilerek Bloom Sınıflandırması'na göre katılımcıların coğrafi bilgi ve becelerileri ile ilgili bilişsel düzey beklentileri tespit edilmiştir.

Bu doğrultuda incelenen sistemler (Özey vd., 2013):

A. Uluslararası Bakalorya Diploma Programı Coğrafya Sınavları (International Baccalaureate Diploma Programme Geography Examinations).

\begin{tabular}{|l|c|c|c|c|c|}
\hline Değerlendirme Hedefleri & Sınav 1 & Sınav 2 & Sınav 3 & Iç Değerlendirme & Ortalama \\
\hline $\begin{array}{l}\text { 1. Belirtilen içeriğe yönelik } \\
\text { bilgi ve anlama }\end{array}$ & $\% 45$ & $\% 35$ & $\% 35^{*}$ & $\% 20$ & $\begin{array}{c}\% 35 \\
\% 30^{*}\end{array}$ \\
\hline $\begin{array}{l}\text { 2. Bilinen ve kavrananlar } \\
\text { üzerinden uygulama ve } \\
\text { analizler }\end{array}$ & $\% 30$ & $\% 30$ & $\% 35^{*}$ & $\% 20$ & $\% 30$ \\
\hline $\begin{array}{l}\text { 3. Sentez ve değerlendirme } \\
\text { 4. Uygun çeșitli beceri ve } \\
\text { tekniklerin seçimi, kullanımı } \\
\text { ve uygulanması }\end{array}$ & $\% 20$ & $\% 25$ & $\% 10^{*}$ & $\% 40$ & $\% 25$ \\
*Genisletimimis ileri sevive ek dersler alan öğrencilere yöneliktir. & & & $\% 10$ \\
\end{tabular}

Genisetilmis lleri sevire ek derster alen äsrencilere väneliktir.

B. Cambridge Üniversitesi Uluslararası Coğrafya Sınavı (University of Cambridge International General Certificate of Secondary Education Geography Examination).

\begin{tabular}{|l|c|c|c|c|}
\hline \multicolumn{1}{|c|}{$\begin{array}{c}\text { Değerlendirme } \\
\text { Hedefleri }\end{array}$} & $\begin{array}{c}\text { Sinav 1 } \\
\text { (Coğrafi } \\
\text { Temalar) }\end{array}$ & $\begin{array}{c}\text { Sinav 2 } \\
\text { (Coğrafi } \\
\text { Beceriler) }\end{array}$ & $\begin{array}{c}\text { Sınav 3 } \\
\text { (Okul-tabanlı) } \\
\text { ya da } \\
\text { (Arazi Çalışması Tabanlı) }\end{array}$ & Toplam \\
\hline Bilgi ve anlama & $\% 21,5$ & $\% 3$ & $\% 5,5$ & $\% 30$ \\
\hline Beceriler ve analiz & $\% 13,5$ & $\% 22$ & $\% 16,5$ & $\% 52$ \\
\hline Yargı ve karar verme & $\% 10$ & $\% 2,5$ & $\% 5,5$ & $\% 18$ \\
\hline Toplam & $\% 45$ & $\% 27,5$ & $\% 27,5$ & $\% 100$ \\
\hline
\end{tabular}

C. College Board İleri Düzey Yerleştirme Programı Beşeri Coğrafya Sınavı (College Board Advanced Placement Human Geography Examination) (Ünlü, 2013).

\begin{tabular}{|c|c|c|c|c|c|}
\hline \multicolumn{2}{|c|}{2012 AP HG Sınavı 2. Bölüm Sorularının Bloom Sınıflandırmasına Göre Analizi } \\
\hline Bilgi & Anlama & Uygulama & Analiz & Sentez & Değerlendirme \\
\hline$\% 25$ & $\% 10$ & $\% 5$ & $\% 10$ & $\% 20$ & $\% 30$ \\
\hline \multicolumn{3}{|c|}{ Alt Düzey Bilişsel Seviye $=\% 40$} & \multicolumn{4}{|c|}{ Üst Düzey Bilişsel Seviye $=\% 60$} \\
\hline
\end{tabular}

D. Ölçme, Seçme ve Yerleştirme Merkezi (ÖSYM) Öğrenci Seçme ve Yerleştirme Sistemi (ÖSYS)(Sönmez, 2013).

\begin{tabular}{|c|c|c|c|c|c|}
\hline Bilgi & Anlama & Uygulama & Analiz & Sentez & Değerlendirme \\
\hline$\% 20.3$ & $\% 57,4$ & $\% 3,7$ & $\% 11,1$ & $\% 1,9$ & $\% 5,6$ \\
\hline \multicolumn{3}{|c|}{ Alt Düzey Bilisssel Seviye $=\% 81,4$} & \multicolumn{3}{|c|}{ Üst Düzey Bilișsel Seviye = 18,6 } \\
\hline
\end{tabular}

\section{Sonuç ve Öneriler}

Türkiye'de ve dünyada coğrafya müfredatlarına bakıldığında inceleme alanlarının ve konu dağılımlarının birbirine çok yakın olduğu görülmektedir. Ancak yapılan ölçme-değerlendirme çaıışmalarına bakıldığında farklılıklar ortaya çıkmaktadır. Bu farklılıklarının ana başlıkları şunlardır:

\section{A. Süreç Değerlendirme}

B. Bloom Taksonomisine Uyumluluk

C. Harita ve Arazi Çalışmalarının Değerlendirilmesi

D. Edinilen Bilgilerin Yaşam İçerisinde Değerlendirilmesi

A. Süreç değerlendirmesi için öğrencilerin eğitim-öğretimleri sırasında portfolyolar oluşturmaları, bu portfolyolarının değerlendirilmesi ve öğrencilere öz değerlendirme imkanı verilerek yaşanan sürecin de nasıl geçirildiğinin fark ettirilmesi sağlanmalıdır.

B. Yapılan tüm sınav değerlendirmelerinde Bloom Taksonomisi'ni içeren değerlendirme sistemi kullanılmalıdır. Özellikle öğrencilerin ve öğretmenlerin ileride ortak proje üretmelerini de sağlayabilecek analiz becerileri mutlaka değerlendirilerek bu değerlendirme sonucunda basamaklandırılmış hedefler oluşturulmuştur.

C. Katıldığımız Uluslararası Coğrafya Olimpiyatı sürecinde gözlemlediğimiz üzere arazi çalışmalarında mekan ve insan, insan ve meken ilişkisi ana bakış açısıdır. Mekan ile insan arasındaki ilişki sorgulanmaktadır. Bu sorgulama sonucunda ortaya çıkan sorulara verilen yanıtların aynı zamanda çalışmanın gerçekleştirildiği arazi üzerinde bir haritalandırma çalışması ile birlikte yürütülmesi beklenmektedir. Coğrafya biliminin temel becerilerinin kullanımının yanı sıra insanın mekanı değiştirme sürecinde ne kadar sürdürülebilir çözümler ürettiği ve geniş fayda ürettiği sorgulanmaktadır. Bu da bir önceki değerlendirmelerde bahsettiğimiz süreç ve Bloom taksonomisine uygun ölçme-değerlendirmelere alışkın öğrenciler tarafindan çok daha kolay başarılmaktadır.

Yaygın değerlendirme yöntemi olarak ülkemizde açık uçlu klasik sınavlar ve çoktan seçmeli sınavlar içerisinde bir ya da iki soru ve geziler ile geçiştirilen harita ve arazi çalışmaları coğrafyanın temel çalışma alanlarıdır. Bu temel alan üzerinde mekanı tasarlama ve kullanma gibi üst bilişsel beceriler geliştirilmesi bek- 
lenmektedir.. Modern dünyada çok kıymetli olan bu beceri için eğitim-öğretimimizde daha fazla yer ayrılmalıdır. Coğrafi Bilgi sistemleri (CBS) kullanımından önce temel haritalandırma ve kullanma becerileri geliştirilmelidir.

D. Kalıcı anlamanın sağlanmasında öğrencinin yaşadığı çevresini sorgulaması ve kendi yaşamı içerisinde değerlendirmeler yapabilmesi gereklidir. Öğrenciler eğitimleri sırasında buna yönlendirilmelidir. Konular işlenirken yakın çevreden ve öğrencilerin yaşamlarından örnekler seçilmelidir. Verilecek projeler ve araştırmalarda öğrencilerin kendi yaşamlarındaki insan ve mekan ilişkinin etkilerini değerlendirmeleri ve çözümler üretebilmeleri beklenmelidir.

Örneğin Advanced Placement ölçme-değerlendirme sistemi ile yetişen bir öğrenci, \%30'luk bir paya sahip değerlendirme basamağında, insan ve mekan ilişkisini sürdürülebilir çözümler ve geniş fayda bakış açısı ile sürekli sorgulamakta ve değerlendirmektedir. Bu yaptığı değerlendirmelerin düzeyi ile başarısı ortaya çıkmaktadır.

Ülkemizde en yaygın olarak uygulanan ÖSYS sisteminde bu alana ayrılan pay ise sadece $\% 5,6^{\prime}$ dır. Ortaöğretimde yapılan öğrenci değerlendirmelerinde ise belirlenmiş bir standart ve kural tarafimızdan tespit edilememiştir.

Modern ülkelerin ölçme-değerlendirme kuralları ortaöğretimde katidir. Bu kurallara göre hazırlanmamış sınavlar öğrencilere asla uygulanmamaktadır. Bunu uygulayan ülkelerde ulusal ve uluslararası sınavlarda ölçme-değerlendirme birliği sağlanmaktadır.

Öğrencilere uygulanan tüm sınavların belli bir kalite standartlarına taşıyacak ön sınav değerlendirme kritelerinin yer aldığı formlar üzerinden değerlendirilmesi beklenmelidir. Bu formlar yazıda bahsettiğimiz uluslararası standartlara göre hazırlanmalıdır. Bu kriterlere göre yapılacak ölçme-değerlendirme çalışmaları arttıkça ülkemizin de uluslararası coğrafya sınavlarındaki katılım ve başarı oranı artacaktır.

\section{Kaynakça}

Özey, R., Kılınç, Y. ve Ateş, M. (2013). Farklı Ülkelerde Coğrafya Eğitimi Ve Öğretimi. Pegem Akademi, Ankara.

Ünlü, M. (2013)."Coğrafya Eğitiminde Öğrenme Alanlarına Göre Ölçme Ve Değerlendirme." 21. Yüzyılda Değişen Yaklaşımlar Ve Yükseköğretimde Coğrafya Eğitimi. Pegem Akademi, s. 153-92. Baskı. Ankara.

Sönmez, Ö. F., Koç, H., ve Çiftçi, T. (2013). "ÖSS, YGS Ve LYS Sınavlarındaki Coğrafya Sorularının Bloom Taksonomisi Bilişsel Alan Düzeyi Açısından Analizi." Karadeniz Araştırmaları Dergisi 36 (2013): 25775.

IGU Online. Web. <http://igu-online.org/>.

The International Geography Olympiad. Web. <http://www.geoolympiad.org/>.

Türk Coğrafya Kurumu. Web. <http://www.tck.org.tr/>.

Cambridge IGCSE Geography Syllabus. 2015. Web. <http://www.cie.org.uk/images/150857-2016-syllabus.pdf>.

AP Human Geography Course Discription. College Board, 2015. Web. $<$ https://secure-media. collegeboard. org/ digitalServices/ pdf/ap/ap-human-geography-course-description.pdf $>$.

IB Diploma Programme Geography Guide. IB Organization, 2015. Web. $<$ http://www.ibo.org/programmes/diploma-programme/curriculum/individuals-and-societies/geography/>. 